\title{
Exposure to Organophosphate and Neonicotinoid Insecticides and Its Association with Steroid Hormones among Male Reproductive-Age Farmworkers in Northern Thailand
}

\author{
Neeranuch Suwannarin 1,2,3 ${ }^{\mathbb{D}}$, Tippawan Prapamontol ${ }^{2, *} \mathbb{D}^{\mathbb{D}}$, Tomohiko Isobe ${ }^{3} \mathbb{D}$, Yukiko Nishihama ${ }^{3}$, \\ Yuki Hashimoto ${ }^{3}$, Ampica Mangklabruks ${ }^{4}$, Tawiwan Pantasri ${ }^{5}$, Somporn Chantara ${ }^{6}$, Warangkana Naksen ${ }^{7}$ \\ and Shoji F. Nakayama ${ }^{3, *(D)}$
}

1 Ph.D. Degree Program in Environmental Science, Environmental Science Research Center, Faculty of Science, Chiang Mai University, Chiang Mai 50200, Thailand; suwannarin.ns@gmail.com

2 Research Institute for Health Sciences (RIHES), Chiang Mai University, Chiang Mai 50200, Thailand

3 Health and Environmental Risk Division, National Institute for Environmental Studies, Tsukuba, Ibaraki 305-8506, Japan; isobe.tomohiko@nies.go.jp (T.I.); nishihama.yukiko@nies.go.jp (Y.N.); hashimoto@scas.co.jp (Y.H.)

4 Department of Internal Medicine, Faculty of Medicine, Chiang Mai University, Chiang Mai 50200, Thailand; ampica.m@cmu.ac.th

check for updates

Citation: Suwannarin, N.; Prapamontol, T.; Isobe, T.; Nishihama, Y.; Hashimoto, Y.; Mangklabruks, A.; Pantasri, T.; Chantara, S.; Naksen, W.; Nakayama, S.F. Exposure to Organophosphate and Neonicotinoid Insecticides and Its Association with Steroid Hormones among Male Reproductive-Age Farmworkers in Northern Thailand. Int. J. Environ. Res. Public Health 2021, 18, 5599. https://doi.org/10.3390/ ijerph18115599

Academic Editor: Jaymie Meliker

Received: 6 April 2021

Accepted: 19 May 2021

Published: 24 May 2021

Publisher's Note: MDPI stays neutral with regard to jurisdictional claims in published maps and institutional affiliations.

Copyright: (C) 2021 by the authors. Licensee MDPI, Basel, Switzerland. This article is an open access article distributed under the terms and conditions of the Creative Commons Attribution (CC BY) license (https:// creativecommons.org/licenses/by/ $4.0 /)$.
5 Department of Obstetrics and Gynecology, Faculty of Medicine, Chiang Mai University, Chiang Mai 50200, Thailand; tawiwan.p@cmu.ac.th

6 Environmental Science Research Center, Faculty of Science, Chiang Mai University, Chiang Mai 50200, Thailand; somporn.chantara@gmail.com

7 Faculty of Public Health, Chiang Mai University, Chiang Mai 50200, Thailand; wnaksen@gmail.com

* Correspondence: tippawan.prapamontol@cmu.ac.th (T.P.); fabre@nies.go.jp (S.F.N.); Tel.: +81-29-850-2786 (S.F.N.)

Abstract: Several studies indicated organophosphate (OP) and neonicotinoid (NEO) insecticides are endocrine disruptors; however, data are scarce. This cross-sectional study recruited 143 male farmworkers aged 18-40 years in Fang district, Chiang Mai province, northern Thailand. OP exposure was assessed by measuring urinary dialkylphosphate (DAPs) using a gas-chromatography flame photometric detector. Urinary NEOs, their metabolites $(\mathrm{NEO} / \mathrm{m})$ and serum steroid hormones were measured using liquid chromatography-tandem mass spectrometry. Characteristics of participants were determined by face-to-face interviews. DAPs and five NEO/m were detected in more than $60 \%$ of samples. The concentration of diethylphosphate was highest among DAP metabolites (geometric mean concentration (GM: $23.9 \mathrm{ng} / \mathrm{mL}$ ) and the concentration of imidacloprid (IMI) was highest among NEO/m (GM: $17.4 \mathrm{ng} / \mathrm{mL}$ ). Linear regression models showed that the IMI level was positively associated with testosterone, dehydrocorticosterone (DHC) and dehydroepiandrosterone (DHEA) levels. Imidacloprid-olefin and DHEA levels were positively associated. Thiamethoxam (THX) were inversely associated with DHC and deoxycorticosterone levels. Clothianidin (CLO), THX and $\mathrm{N}$-desmethyl-acetamiprid levels were positively associated with the androstenedione level. CLO and THX levels were inversely associated with the cortisone level. In conclusion, the association between NEO insecticides exposure and adrenal androgens, glucocorticoids and mineralocorticoids, suggest potential steroidogenesis activities. Our findings warrant further investigation.

Keywords: organophosphates; dialkylphosphates; neonicotinoids; insecticides; metabolites; occupational health; environmental health; reproductive hormones; steroid hormones; farmworker

\section{Introduction}

Insecticides are widely used around the world in agricultural settings and households for pest control [1]. Several studies demonstrated that insecticides are linked with neurotoxicity, immunotoxicity, carcinogenesis, endocrine disruption and reproductive health 
effects [2-8]. Exposure to pesticides including organochlorine, carbamate and organophosphate (OP) is linked with alterations of hormones, including luteinizing hormone (LH), follicle-stimulating hormone (FSH), inhibin B, prolactin, estradiol and testosterone [9-14]. Several investigations have reported a decline in sperm concentrations and sperm counts related to pesticides, leading to poor semen quality and reproductive hormones alterations in males [12,15]. A recent study of farmworkers in northern Thailand investigated the associations of pesticides with testosterone [16]. It found an association between OP metabolites and total testosterone; however, statistical significance association might be random due to the small sample size [16].

A few animal studies reported that exposure to neonicotinoids (NEOs) leads to reproductive abnormalities, mostly in rats and mice. Kapoor et al. (2011) investigated the impact of oral exposure to various concentrations $(5,10$ and $20 \mathrm{mg} / \mathrm{kg} /$ day) of imidacloprid (IMI) on the reproductive system of female rats and showed that rats treated with $20 \mathrm{mg} / \mathrm{kg}$ / day IMI exhibited follicular changes and reduced ovarian weight [17]. Bal et al. (2011) revealed that testosterone levels were significantly lower in male rats treated with $8 \mathrm{mg} / \mathrm{kg} /$ body weight IMI and $32 \mathrm{mg} / \mathrm{kg} /$ body weight clothianidin (CLO) than in the control group [18,19]. Bal et al. (2013) showed that the testosterone level of adult male rats orally treated with CLO did not significantly differ from that in the control group, but the reproductive system was affected [20]. Gu et al. (2013) found that exposure to IMI and acetamiprid (ACE) adversely affects fertilization in mice [21]. These findings reveal that exposure to NEOs is detrimental to mammalian sperm. In utero and lactational exposure studies have reported that low dose $(1 \mathrm{mg} / \mathrm{kg})$ and high dose $(10 \mathrm{mg} / \mathrm{kg})$ of ACE exposure in mice did not affect the testosterone levels [22]. Epidemiological studies found that maternal exposure to IMI is linked with a high risk of tetralogy of Fallot, congenital heart defects, newborn anencephaly and maternal exposure to ACE is linked with low birthweight [23-26]. A few studies demonstrated the health effects, including DNA damage and impaired lung function, of exposure to NEOs via a pesticide sprayer [27]. To the best of our knowledge, no study has investigated the associations between concentrations of NEOs and endocrine and reproductive hormones in humans.

Exposure to OP and NEO insecticides may affect steroid hormone levels. Steroids including androstenedione and dehydroepiandrosterone (DHEA) are precursors of sex hormones and are produced in the adrenal glands and gonads [28]. Although testosterone is predominantly produced in the gonads by Leydig cells, $5 \%$ is generated from the precursors androstenedione and DHEA [28]. Cortisol and cortisone are glucocorticoids and deoxycorticosterone (DOC) and dehydrocorticosterone (DHC) are mineralocorticoids released by the adrenal glands within the adrenal cortex [29,30]. However, little is known about occupational exposure to OPs and NEOs and its effects on steroid hormones.

We previously reported that Thai reproductive-aged farmworkers are exposed to OPs and NEOs based on measurement of urinary dialkylphosphates (DAPs), nonspecific metabolites of OPs, and NEOs and their metabolites (NEO/m) [31]. In that study, we found that exposure to NEOs is related to alterations of red blood cell indices in male farmworkers (a separate manuscript is being prepared). Furthermore, we did not observe any association between DAP concentrations and hematological parameters; however, previous studies reported associations between DAP metabolites and hormones $[15,32,33]$. Although data are available about the relationship between OP exposure and reproductive health and steroid hormones, little has been reported about the association between NEO exposure and human health. The objective of this study was to evaluate the associations between exposure to OP and NEO insecticides, assessed by measuring DAP and NEO/m concentrations and serum steroid hormones in male farmworkers.

\section{Materials and Methods}

\subsection{Study Area and Study Participants}

This cross-sectional study included reproductive-age farmworkers aged 18-40 years who worked at least 3 days per week as a farmworker and had no evidence of chronic 
diseases (such as diabetes, liver illness, renal insufficiency or cancer) or endocrine diseases. A total of 144 farmworkers were informed of the objectives and invited to participate in the study. Study participants were enrolled at the health-promoting hospital in Fang district, Chiang Mai province, Thailand. Participants were asked to provide written informed consent prior to face-to-face interviews using questionnaires and sample collection. One male failed to provide a blood sample, while 143 male participants provided blood samples and completed questionnaires. Each individual was directly interviewed regarding their sociodemographic characteristics and work and exposure characteristics.

\subsection{Collection of Urine Samples}

Spot urine samples were collected in $50 \mathrm{~mL}$ polypropylene containers. About 10 and $4 \mathrm{~mL}$ urine samples were required for biomonitoring of OP metabolites and $\mathrm{NEO} / \mathrm{m}$ analysis, respectively. All aliquoted spot urine samples were kept at $-20{ }^{\circ} \mathrm{C}$ at the field site prior to transfer to the toxicology laboratory at Research Institute for Health Sciences (RIHES), Chiang Mai University and stored at $-20^{\circ} \mathrm{C}$ until analyses. In addition, $4 \mathrm{~mL}$ urine samples were shipped on dry ice to the Health and Environmental Risk Division, National Institute Research for Environmental Studies (NIES), Tsukuba, Japan and then stored at $-80^{\circ} \mathrm{C}$ until analyses.

\subsection{Collection of Blood Samples}

Non-fasting blood samples were collected in the morning between 05:00 a.m. and 12:00 p.m. (four blood samples were collected after 12:00 p.m.), deposited in vacutainer tubes without anticoagulant (BD vacutainers; Becton Dickinson, NJ, USA) and centrifuged to obtain serum samples. All serum samples were kept at $-20{ }^{\circ} \mathrm{C}$ at the laboratory field site prior to transfer to the toxicology laboratory at RIHES, Chiang Mai University and kept at $-80{ }^{\circ} \mathrm{C}$ until analyses. In addition, all serum samples were shipped to NIES, Tsukuba, Japan and stored at $-80^{\circ} \mathrm{C}$ until analyses.

\subsection{Collection of Data}

The structured questionnaire was modified from the pilot study [31]. Reliability and validity were tested as quality control $(\mathrm{QC})$ of the questionnaire. Each individual was directly interviewed regarding their sociodemographic factors (age, education level, monthly income), alcohol consumption, smoking status, task activities related to pesticide use (total number of years spent as a farmworker, number of days per week and hours per day worked in the field, occupational status and frequency of and last pesticide use). Trained project staff took anthropometric measurements (weight and height) and conducted the questionnaire.

\subsection{Measurement of Urinary OP Metabolites}

Urinary OP metabolites including dimethylphosphate (DMP), dimethylthiophosphate (DMTP), diethylphosphate (DEP), diethylthiophosphate (DETP) and diethyldithiophosphate (DEDTP) were measured by gas chromatography with a flame photometric detector according to the previously established method using an Agilent 7890-B GC system (Agilent Technologies, Inc., Santa Clara, CA, USA) [34]. The procedure was briefly described in our previous study [31].

\subsection{Measurement of Urinary NEO/m}

Urinary NEO/m including ACE, CLO, dinotefuran (DIN), flonicamid (FLN), IMI, nitenpyram (NIT), sulfoxaflor (SUF), thiacloprid (THI), thiamethoxam (THX), desmethylCLO (dm-CLO), N-desmethyl-ACE (N-dm-ACE), imidacloprid-olefin (Of-IMI) and thiacloprid-amide (THI-AM) were measured by liquid chromatography-tandem mass spectrometry (LC-MS/MS). The procedure used a Nexera liquid chromatography system coupled to a Triple Quad 8060 mass spectrometer (Shimadzu Corporations, Kyoto, Japan) and was briefly described in our previous study [31]. 


\subsection{Measurement of Serum Steroid and Reproductive Hormones}

Concentrations of cortisol, cortisone, DHC, testosterone, DOC, DHEA and androstenedione were measured by LC-MS/MS. The procedures were modified from previous published methods [35,36]. Briefly, $200 \mu \mathrm{L}$ of serum was transferred to a $10 \mathrm{~mL}$ glass tube and $20 \mu \mathrm{L}$ of internal standard was added. After gentle shaking, $800 \mu \mathrm{L}$ of water:methanol:acetic acid (90:10:1, $v / v / v)$ was added and mixed for $30 \mathrm{~s}$. The sample was applied to a SPE cartridge, which was preconditioned with $1 \mathrm{~mL}$ of methanol, centrifuged at $2000 \times g$ for $1 \mathrm{~min}$, exposed to $1 \mathrm{~mL}$ of $100 \mathrm{mM}$ ammonium bicarbonate:25\% ammonia water (50:2, $v / v)$, centrifuged at $2000 \times g$ for $1 \mathrm{~min}$, exposed to $1 \mathrm{~mL}$ of water:acetonitrile $(1: 9, v / v)$, centrifuged at $2000 \times g$ for $1 \mathrm{~min}$ and exposed to $1 \mathrm{~mL}$ of water:acetonitrile:acetic acid $(90: 10: 1, v / v / v)$. The conditioned cartridge was loaded with the prepared serum sample and centrifuged at $2000 \times g$ for $1 \mathrm{~min}$. The pretreated serum sample was washed with $1 \mathrm{~mL}$ of $25 \%$ methanol and centrifuged at $2000 \times \mathrm{g}$ for $1 \mathrm{~min}$, treated with $1 \mathrm{~mL}$ of $100 \mathrm{mM}$ ammonium bicarbonate: $25 \%$ ammonia water $(50: 2, v / v)$ and centrifuged at $2000 \times g$ for $1 \mathrm{~min}$. Then, the pretreated serum sample and SPE cartridge were transferred to another test tube and eluted with $1 \mathrm{~mL}$ of water:acetonitrile $(1: 9, v / v)$. The pretreated sample was dried with a gentle nitrogen stream at $45^{\circ} \mathrm{C}$ for $15 \mathrm{~min}$. Residues was reconstituted with $100 \mu \mathrm{L}$ of $30 \%$ methanol prepared with water. The eluate was injected into a Nexera liquid chromatography system coupled to a Triple Quad 8060 mass spectrometer (Shimadzu Corporations).

\subsection{QC and Quality Assurance}

\subsubsection{Analyses of Urinary OP Metabolites}

Urine samples were pooled from anonymous non-farming volunteers and used as QC samples. QC urine samples were fortified with a standard solution containing DMP (25 ng/mL), DEP (10 ng/mL), DMTP (12 ng/mL), DMDTP (4 ng/mL), DETP (4 ng/mL) and DEDTP $(2 \mathrm{ng} / \mathrm{mL})$. These samples were analyzed for reproducibility precision. Five replicates of QC samples were analyzed by a single operator in a single day for within-day precision. For between-day precision, five $\mathrm{QC}$ samples were analyzed by a single operator on three consecutive days. Recovery ranged from $81.9 \%$ to $104.1 \%$, with relative standard deviation ranging from $2.4 \%$ for DMTP to $14.2 \%$ for DEDTP for within-day precision and from $4.5 \%$ for DMTP to $20.0 \%$ for DMP for between-day precision. Six calibration points were set to range from 6.25 to $100 \mathrm{ng} / \mathrm{mL}$ for DMP, 3 to $96 \mathrm{ng} / \mathrm{mL}$ for DMTP, 1 to $32 \mathrm{ng} / \mathrm{mL}$ for DMDTP, 1.25 to $40 \mathrm{ng} / \mathrm{mL}$ for DEP, 0.25 to $64 \mathrm{ng} / \mathrm{mL}$ for DETP and 0.5 to $16 \mathrm{ng} / \mathrm{mL}$ for DEDTP with the coefficient of determination $\left(R^{2}\right)$ exceeding 0.997 . The concentration of dibutyl phosphate, which was used as an internal standard, was $25 \mathrm{ng} / \mathrm{mL}$. Method detection limits (MDLs) were defined as the concentration of a compound that yielded a signal-to-noise ratio of 3 .

\subsubsection{Analyses of Urinary $\mathrm{NEO} / \mathrm{m}$}

Urine samples were collected from pregnant volunteers from Japan and pooled as QC samples. These samples were spiked with the following concentrations of $\mathrm{NEO} / \mathrm{m}$ standards: ACE, THI and SUF $(0.05 \mathrm{ng} / \mathrm{mL})$, THI-AM $(0.1 \mathrm{ng} / \mathrm{mL})$, THX $(0.2 \mathrm{ng} / \mathrm{mL})$, DIN, CLO, IMI, NIT and N-dm-ACE $(0.5 \mathrm{ng} / \mathrm{mL})$, FLN $(1 \mathrm{ng} / \mathrm{mL}), \mathrm{dm}-\mathrm{CLO}(2 \mathrm{ng} / \mathrm{mL})$ and Of-IMI $(10 \mathrm{ng} / \mathrm{mL})$. The QC samples were analyzed as part of quality quarantine and the results were recorded in a Shewhart control chart ( $\bar{X}-\mathrm{R}$ control chart) based on ISO 7870 (International Organization for Standardization, Geneva, Switzerland). The MDLs were estimated using the following equation:

$$
\mathrm{MDL}=\mathrm{t}_{(n-1,0.05)} \times 2 \times \mathrm{s}
$$

where $t_{(n-1,0.05)}$ represents the Student's t value under an $\alpha$ level of 0.05 with $n-1$ degrees of freedom and s represents the standard deviation (SD) of blank measurements in $n$ replicates $(n \geq 7)$. Eight calibration points for each analyte were set to range from 0.0025 to $0.5 \mathrm{ng} / \mathrm{mL}$ for ACE, THI, SUF and THI-AM, 0.01 to $2.0 \mathrm{ng} / \mathrm{mL}$ for THX, 0.025 to $5.0 \mathrm{ng} / \mathrm{mL}$ 
for DIN, CLO, IMI, NIT and N-dm-ACE, 0.05 to $10.0 \mathrm{ng} / \mathrm{mL}$ for FLN, 0.1 to $20.0 \mathrm{ng} / \mathrm{mL}$ for $\mathrm{dm}-\mathrm{CLO}$ and 0.5 to $100.0 \mathrm{ng} / \mathrm{mL}$ for Of-IMI. The concentration of the internal standard was $0.1 \mathrm{ng} / \mathrm{mL}$ for ACE and THI, $0.2 \mathrm{ng} / \mathrm{mL}$ for SUF and THI-AM, $1.0 \mathrm{ng} / \mathrm{mL}$ for DIN, CLO, IMI and NIT, $2.0 \mathrm{ng} / \mathrm{mL}$ for N-dm-ACE, $4.0 \mathrm{ng} / \mathrm{mL}$ for FLN, $8.0 \mathrm{ng} / \mathrm{mL}$ for $\mathrm{dm}$ CLO and $20.0 \mathrm{ng} / \mathrm{mL}$ for Of-IMI. The $\mathrm{R}^{2}$ exceeded 0.99 . The coefficient of variation was $<14.5 \%$ for duplicate analyses of samples conducted every analytical batch of 40 samples during measurement.

\subsubsection{Analyses of Serum Steroid Hormones}

Commercial serum samples were used as QC samples. They were spiked with the following concentrations of steroid hormone standards: $1 \mu \mathrm{g} / \mathrm{mL}$ for androstenedione, DHC and testosterone, $10 \mu \mathrm{g} / \mathrm{mL}$ for cortisol, $3 \mu \mathrm{g} / \mathrm{mL}$ for cortisone and DHEA and $0.3 \mu \mathrm{g} / \mathrm{mL}$ for DOC. The QC samples were analyzed as part of quality quarantine and mean concentrations $\pm 10 \%$ were recorded in a control chart. All QC samples were well within the control chart during measurement day. The MDLs were estimated using Equation (1). A stock standard solution was diluted to prepare calibration curves with at least six points for each analyte with the following concentration ranges: $0.03-100 \mathrm{ng} / \mathrm{mL}$ for androstenedione and testosterone, $1-300 \mathrm{ng} / \mathrm{mL}$ for cortisol, $0.3-300 \mathrm{ng} / \mathrm{mL}$ for cortisone, 0.01-30 ng/mL for DOC, $0.1-1000 \mathrm{ng} / \mathrm{mL}$ for DHEA and 0.03-10 ng/mL for DHC, while the internal standard was used at $10 \mathrm{ng} / \mathrm{mL}$ for androstenedione and DOC, $100 \mathrm{ng} / \mathrm{mL}$ for cortisol, cortisone and DHEA and $50 \mathrm{ng} / \mathrm{mL}$ for testosterone. The $\mathrm{R}^{2}$ exceeded 0.99 . The coefficient of variation was less than $16.3 \%$ for duplicate analysis of samples conducted every analytical batch of 50 samples during measurement.

\subsection{Statistical Analysis}

Sociodemographic characteristics of the study population were reported as the frequency distribution or mean $\pm \mathrm{SD}$. Correlation of general characteristics and urinary concentrations of DAPs and NEO/m were analyzed using Spearman's correlation coefficient, with a $p$-value of less than 0.05 considered significant. Urinary concentrations of $\mathrm{DAPs}$ and NEO/m were normalized relative to specific gravity (SG) in the same samples to adjust for urine dilution; these concentrations were therefore reported as $\mathrm{ng} / \mathrm{mL}$. Concentrations were corrected for SG using the following adapted formula [37]:

$$
\mathrm{P}_{\mathrm{c}}=\mathrm{P}\left[\left(\mathrm{SG}_{\mathrm{Med}}-1 / \mathrm{SG}_{\text {Meas }}-1\right)\right]
$$

where $\mathrm{P}_{\mathrm{c}}$ is the SG-corrected metabolite concentration, $\mathrm{P}$ is the observed metabolite concentration, $\mathrm{SG}_{\mathrm{Med}}$ is the median $\mathrm{SG}$ of all samples tested in the study and $\mathrm{SG}_{\mathrm{Meas}}$ is the measured SG of the individual urine sample. The concentrations of DAPs and $\mathrm{NEO} / \mathrm{m}$ were assessed to check normality using the Kolmogorov-Smirnov test and log10-transformed to obtain normal distributions before statistical analyses. Summary statistics were computed using the NADA package (version 1.6-1.1) in the statistical R software. Geometric means (GM) and geometric standard deviations (GSDs) were calculated for analytes detected in $>50 \%$ of samples. The total concentrations of dimethylalkylphosphates (sumDMP), diethylalkylphosphates (sumDEP) and DAPs (sumDAP) were used to determine the association between OP exposure and steroid hormones. To calculate total concentrations of sumDMP, sumDEP and sumDAP, mass concentrations in urine $(\mathrm{ng} / \mathrm{mL})$ were converted to molar concentrations (nmol/L) with correction for SG using the following molecular masses in g/mol: 126.05 (DMP), 142.10 (DMTP), 158.18 (DMDTP), 154.10 (DEP), 169.16 (DETP) and 186.23 (DEDTP). SumDMP was defined as the molar sum of DMP, DMTP and DMDTP. SumDEP were defined as the molar sum of DEP, DETP and DEDTP. SumDAP was defined as the molar sum of all DAP metabolites. The concentrations of sumDMP, sumDEP and sumDAP in nmol/L and the concentrations of CLO, IMI, THX, N-dm-ACE and Of-IMI in $\mathrm{ng} / \mathrm{mL}$ were treated as continuous variables ( $\log 10$-transformed) in subsequent analysis. The concentrations of androstenedione, cortisol, cortisone, DHEA, DHC, DOC and testosterone were also log-transformed to reduce skewness. Subject-related sociodemographic 
characteristics and work, exposure and reproductive health characteristics of the study population with missing data were computed by the multivariate imputation by chained equations (MICE) method, with 10 imputations and 10 iterations using MICE package (version 3.13.0) prior to multivariate linear regression analysis. In addition, detected urinary concentrations below the MDL were imputed with quantile regression approach for left-censored missing (QRILC) for subsequent statistical analysis. Linear regression models were used to assess the association between each DAP and NEO/m concentrations and steroid hormone concentrations, with the $\alpha$ level set to 0.05 . In each model, the urinary $\mathrm{DAP}$ and $\mathrm{NEO} / \mathrm{m}$ concentration was the independent variable while the serum steroid hormone was the dependent variable. Each model was adjusted for age, body mass index (BMI), smoking status, alcohol consumption, ethnicity, education level, monthly income, total number of years spent as farmworker, status of farmworker, number of days per week and hours per day worked in the field, duration of last pesticide use prior to sample collection and hematological status based on current scientific knowledge $[9,16]$.

\section{Results}

\subsection{Characteristics of Study Participants}

The general characteristics of the study population are provided in Table 1. This reproductive-age population had a mean (SD) age of 30.1 (5.8) years. About $50 \%$ of participants were normal weight, while some participants were obese class I $(19 \%)$ and overweight (18\%) according to the Regional Office for the Western Pacific standard [38]. In total, $56 \%$ of participants had no formal education, $28 \%$ completed primary school and less than $9 \%$ completed high school, had a technical/professional education or attained a university or higher degree. The monthly individual income of participants was $~ 300$ USD ( $9200 \mathrm{THB})$. In total, $54 \%$ of participants were current smokers, $13 \%$ were former smokers, $33 \%$ were nonsmokers and $85 \%$ consumed alcohol. The Spearman's correlation coefficients between urinary DAP and NEO/m and general characteristics are provided in Table S1. Correlation was negligible between BMI and urinary concentrations of sumDMP, sumDEP, sumDAP, THX, N-dm-ACE and Of-IMI (correlation coefficient $=-0.19,-0.27,-0.27$, $-0.09,-0.26,-0.23$, respectively). Negligible correlation was also found in the relationship between monthly income and urinary concentrations of sumDEP, sumDAP, IMI and OfIMI (correlation coefficient $=0.14,0.15,0.11,0.15$, respectively). There was a negligible correlation between smoking status and urinary concentration of sumDMP, sumDAP, and Of-IMI (correlation coefficient $=0.19,0.17,0.17$, respectively). No correlations were observed between DAP and NEO/m and alcohol consumption. There was a weak negative correlation between educational level and urinary concentration of sumDMP, sumDEP, sumDAP, IMI and Of-IMI (correlation coefficient $=-0.32,-0.32,-0.35,-0.24,-0.30$, respectively). In the study area, OP, mainly chlorpyrifos, dichlorvos, ethion, profenofos, triazophos, and NEO insecticides including IMI and DIN are commonly used which is evidenced by a local retailer shop in the community.

Table 1. General characteristics of the study populations $(n=143)$.

\begin{tabular}{cc}
\hline General Characteristics & $\boldsymbol{n} \mathbf{( \% )}$ \\
\hline Age $(18-40$ years $)(n=143)$ & $30.1(5.8)$ \\
Mean (SD) & \\
Body mass index $\left(\mathrm{kg} / \mathrm{m}^{2}\right)(n=142)$ & $23.5(4.3)$ \\
Mean (SD) & $5(3.5)$ \\
$<18.5$ (underweight) & $71(50.0)$ \\
$18.5-23.0$ (normal weight) & $26(18.2)$ \\
$23.0-25.0$ (overweight) & $27(18.9)$ \\
$25.0-30.0$ (obese class I) & $12(8.4)$ \\
$\geq 30.0$ (obese class II) & $2(1.4)$ \\
\hline
\end{tabular}


Table 1. Cont.

\begin{tabular}{|c|c|}
\hline General Characteristics & $n(\%)$ \\
\hline \multicolumn{2}{|l|}{ Ethnicity $(n=143)$} \\
\hline Thai & $11(7.7)$ \\
\hline Other (Hmong, Tai Yai, Burmese, Palong, Lahu) & $132(92.3)$ \\
\hline \multicolumn{2}{|l|}{ Educational level $(n=143)$} \\
\hline Illiterate/no formal education & $81(56.6)$ \\
\hline Primary school & $40(28.0)$ \\
\hline High school & $12(8.4)$ \\
\hline Technical/professional & $5(3.5)$ \\
\hline University or higher degree & $5(3.5)$ \\
\hline \multicolumn{2}{|l|}{ Individual income $(n=139)$} \\
\hline Mean (SD) (THB/month) & $9200(12,000)$ \\
\hline \multicolumn{2}{|l|}{ Smoking status $(n=143)$} \\
\hline Never smoked/nonsmoker & $48(33.6)$ \\
\hline Former smoker & $18(12.6)$ \\
\hline Current smoker & $77(53.8)$ \\
\hline \multicolumn{2}{|l|}{ Alcohol consumption $(n=143)$} \\
\hline No & $22(15.4)$ \\
\hline Yes & $121(84.6)$ \\
\hline \multicolumn{2}{|l|}{ Sampling characteristics } \\
\hline \multicolumn{2}{|l|}{ Month of sampling $(n=143)$} \\
\hline June & $27(16.8)$ \\
\hline July & $84(58.7)$ \\
\hline August & $29(20.3)$ \\
\hline September & $6(4.2)$ \\
\hline \multicolumn{2}{|l|}{ Time of urine collection $(n=143)$} \\
\hline 05:00-12:00 & $137(95.8)$ \\
\hline 12:01-18:00 & $6(4.2)$ \\
\hline \multicolumn{2}{|l|}{ Time of blood collection $(n=143)$} \\
\hline $05: 00-12: 00$ & $139(97.2)$ \\
\hline 12:01-18:00 & $4(2.8)$ \\
\hline \multicolumn{2}{|l|}{ Total number of years spent as a farmworker } \\
\hline Mean (SD) & $8.9(6.4)$ \\
\hline \multicolumn{2}{|l|}{ Total number of days per week worked in the field } \\
\hline Mean (SD) & $8.1(1.8)$ \\
\hline \multicolumn{2}{|l|}{ Total number of hours per day worked in the field } \\
\hline Mean (SD) & $5.5(1.7)$ \\
\hline \multicolumn{2}{|l|}{ Status of farmworker } \\
\hline Working on own farm or family farm; owner & $64(45.0)$ \\
\hline Working on another person's farm; permanent laborer & $63(44.4)$ \\
\hline Working on a rented farm & $15(10.6)$ \\
\hline $\mathrm{NA}$ & $1(0.7)$ \\
\hline \multicolumn{2}{|l|}{ Last pesticide use } \\
\hline $\begin{array}{l}\text { Three days prior to urine collection and the day of } \\
\text { urine collection }\end{array}$ & $66(46.2)$ \\
\hline Two weeks ago & $24(16.8)$ \\
\hline One month ago & $5(3.5)$ \\
\hline$>$ One month ago & $14(9.8)$ \\
\hline Do not know & $34(23.8)$ \\
\hline
\end{tabular}

Abbreviations: SD, standard deviation; USD, United States Dollar; THB, Thai Baht; NA, no answer. Results are reported as mean (SD) or $n(\%)$. 


\subsection{Urinary DAP and $N E O / m$ Concentrations}

Table 2 shows the detection frequencies and the GMs, selected percentiles and maximums of urinary DAP and NEO/m concentrations. DAP metabolites with diethyl moieties were mostly detected at higher concentrations than those with dimethyl moieties. Five $\mathrm{NEO} / \mathrm{m}$ (CLO, IMI, THX, N-dm-ACE and Of-IMI) were detected at higher than the MDL in more than $60 \%$ of cases and were analyzed further. The GM concentration of DETP was highest $(23.9 \mathrm{ng} / \mathrm{mL})$, followed by DEP $(20.7 \mathrm{ng} / \mathrm{mL})$ and DEDTP $(9.3 \mathrm{ng} / \mathrm{mL})$. Among $\mathrm{NEO} / \mathrm{m}$, the GM concentration of IMI was highest $(17.4 \mathrm{ng} / \mathrm{mL})$, followed by N-dm-ACE $(15.8 \mathrm{ng} / \mathrm{mL})$, THX $(9.1 \mathrm{ng} / \mathrm{mL})$, CLO $(7.4 \mathrm{ng} / \mathrm{mL})$ and Of-IMI $(5.1 \mathrm{ng} / \mathrm{mL})$.

Table 2. Detection frequency and geometric mean (GM), geometric standard deviation (GSD), minimum, maximum and selected percentiles of urinary DAP and NEO/m concentrations among reproductive-age farmworkers $(n=143)$.

\begin{tabular}{|c|c|c|c|c|c|c|c|c|c|}
\hline \multirow{2}{*}{$\begin{array}{l}\text { Compound } \\
\text { (ng/mL) }\end{array}$} & \multirow{2}{*}{ MDL } & \multirow{2}{*}{$\begin{array}{c}>\text { MDL } \\
(\%)\end{array}$} & \multirow{2}{*}{ GM } & \multirow{2}{*}{ GSD } & \multicolumn{5}{|c|}{ Quartiles } \\
\hline & & & & & P25 & P50 & P75 & P95 & Max. \\
\hline \multicolumn{10}{|l|}{ DAP: } \\
\hline DMP & 5.0 & 28.7 & - & - & - & - & - & 12.6 & 73.4 \\
\hline DMTP & 1.0 & 44.8 & - & - & - & - & 2.8 & 37.0 & 134 \\
\hline DMDTP & 0.5 & 25.2 & - & - & - & - & - & 5.2 & 398 \\
\hline DEP & 1.0 & 100.0 & 20.7 & 4.5 & 3.8 & 9.5 & 24.7 & 150 & 5678 \\
\hline DETP & 0.125 & 99.3 & 23.9 & 4.2 & 3.1 & 7.4 & 25.3 & 123 & 445 \\
\hline DEDTP & 0.25 & 79.0 & 9.3 & 6.1 & 0.7 & 2.2 & 11.9 & 67.3 & 386 \\
\hline \multicolumn{10}{|l|}{$\mathrm{NEO} / \mathrm{m}:$} \\
\hline $\mathrm{ACE}$ & 0.0011 & 46.9 & - & - & - & - & 0.006 & 0.1 & 1.5 \\
\hline CLO & 0.007 & 96.5 & 7.4 & 3.6 & 0.04 & 0.1 & 0.2 & 1.0 & 14.6 \\
\hline DIN & 0.003 & 16.1 & - & - & - & - & - & 0.3 & 1.0 \\
\hline FLN & 0.01 & 16.8 & - & - & - & - & - & - & 0.02 \\
\hline IMI & 0.009 & 99.3 & 17.4 & 5.5 & 0.06 & 0.2 & 0.9 & 4.7 & 24.6 \\
\hline NIT & 0.007 & 3.5 & - & - & - & - & - & - & 0.3 \\
\hline THI & 0.0009 & 4.9 & - & - & - & - & - & - & 0.009 \\
\hline THX & 0.003 & 97.2 & 9.1 & 4.9 & 0.03 & 0.07 & 0.3 & 1.9 & 75.8 \\
\hline SUF & 0.002 & 35.7 & - & - & - & - & - & 0.04 & 0.3 \\
\hline $\mathrm{dm}-\mathrm{CLO}$ & 0.03 & 29.4 & - & - & - & - & 0.07 & 0.6 & 4.1 \\
\hline N-dm-ACE & 0.007 & 99.3 & 15.8 & 3.7 & 0.1 & 0.3 & 0.6 & 4.1 & 18.1 \\
\hline Of-IMI & 0.2 & 64.3 & 5.1 & 5.3 & - & 0.7 & 3.5 & 17.9 & 253 \\
\hline THI-AM & 0.002 & 0.7 & - & - & - & - & - & 0.02 & 0.04 \\
\hline
\end{tabular}

Abbreviations: MDL, method detection limit; $\mathrm{ng} / \mathrm{mL}$, nanograms per milliliter; GM, geometric mean; GSD, geometric standard deviation; P25, 25th percentile; P50, 50th percentile; P75, 75th percentile; P95, 95th percentile; Max., maximum concentration; DAP, dialkylphosphate; DMP, dimethylphosphate; DMTP, dimethylthiophosphate; DMTDP, dimethyldithiophosphate; DEP, diethylphosphate; DETP, diethylthiophosphate; DETDP, diethyldithiophosphate; NEO/m, neonicotinoids and their metabolites; ACE, acetamiprid; CLO, clothianidin; DIN, dinotefuran; IMI, imidacloprid; NIT, nitenpyram; SUF, sulfoxaflor; THI, thiacloprid; THX, thiamethoxam; FLN, flonicamid; N-dm-ACE, N-desmethyl-ACE; dm-CLO, desmethyl-clothianidin; THI-AM, thiacloprid-amide; Of-IMI, imidacloprid-olefin; -, values lower than MDLs.

\subsection{Serum Steroid Hormone Concentrations}

The distributions of all measured steroid and reproductive hormone levels in farmworkers are provided in Table 3. The detection rates of androstenedione, cortisol, cortisone, DHC, DHEA, DOC and testosterone were $100 \%$ among 143 farmworkers. The mean concentrations of androstenedione, cortisol, cortisone, DHC, DHEA, DOC and testosterone were $0.8,140,24.7,1.0,3.3,0.9$ and $6.5 \mathrm{ng} / \mathrm{mL}$, respectively. 
Table 3. Steroid hormone concentrations in the study population $(n=143)$.

\begin{tabular}{cccccccc}
\hline $\begin{array}{c}\text { Steroid Hormone } \\
(\mathbf{n g} / \mathbf{m L})\end{array}$ & $\begin{array}{c}\text { Mean } \\
\text { (SD) }\end{array}$ & Min. & P25 & P50 & P75 & P95 & Max. \\
\hline Androstenedione & $0.8(0.3)$ & 0.3 & 0.6 & 0.7 & 1.0 & 1.4 & 2.4 \\
Cortisol & $140(67.6)$ & 5.5 & 91.9 & 127 & 178 & 278 & 379 \\
Cortisone & $24.7(9.1)$ & 1.0 & 18.5 & 23.0 & 29.8 & 42.6 & 55.1 \\
DHC & $1.0(0.7)$ & 0.07 & 0.5 & 0.8 & 1.3 & 2.2 & 3.4 \\
DHEA & $3.3(1.8)$ & 0.5 & 2.0 & 2.9 & 4.4 & 6.7 & 10.0 \\
DOC & $0.9(0.5)$ & 0.1 & 0.5 & 0.8 & 1.1 & 1.7 & 3.6 \\
Testosterone & $6.5(3.1)$ & 1.5 & 4.4 & 5.9 & 7.9 & 12.1 & 19.9
\end{tabular}

Abbreviations: SD, standard deviation; ng/mL, nanograms per milliliter; Min, minimum concentration; P25, 25th percentile; P50, 50th percentile; P75, 75th percentile; P95, 95th percentile; Max. maximum concentration; DHC, dehydrocorticosterone; DHEA, dehydroepiandrosterone; DOC, deoxycorticosterone.

\subsection{Associations between DAP and NEO/m Concentrations and Serum Steroid Hormones}

Linear regression models for each urinary DAP and NEO/m concentrations and association with serum steroid hormones are shown in Figure 1. The urinary concentrations of DAP were grouped as total of three dimethylalkylphosphate (sumDMP: DMP+DMTP+ DMDTP), total of three diethylalkylphosphate (sumDEP: DEP+DETP+DEDTP), total of dialkylphosphate (sumDAP: sumDMP+sumDEP) and the urinary concentrations of NEO/m were shown as individual including CLO, THX, N-dm-ACE, IMI and Of-IMI. The same model was fitted for all the exposure measures: each urinary DAP and NEO/m concentration was introduced into the linear regression model separately and adjusted for age, body mass index, smoking status, alcohol consumption, ethnicity, education level, individual income, total number of years spent as a farmworker, occupational status, number of days per week and hours per day worked in the field, duration of last pesticide use prior to sample collection and hematological status. In each model, log10-transformed urinary concentration of DAPs and $\mathrm{NEO} / \mathrm{m}$ was the independent variable whereas log-transformed serum steroid hormone was the dependent variable. Androstenedione levels showed a significant positive association with CLO, THX and N-dm-ACE concentrations. Cortisone levels showed a significant negative association with CLO and THX concentrations. DHEA levels showed a significant positive association IMI and Of-IMI concentrations. DHC and testosterone levels were positively associated with IMI concentrations. DHC and DOC levels were negatively associated with THX concentration. No significant associations were observed between concentrations of steroid hormones and DAPs. 
$0.6 \cdot(a)$

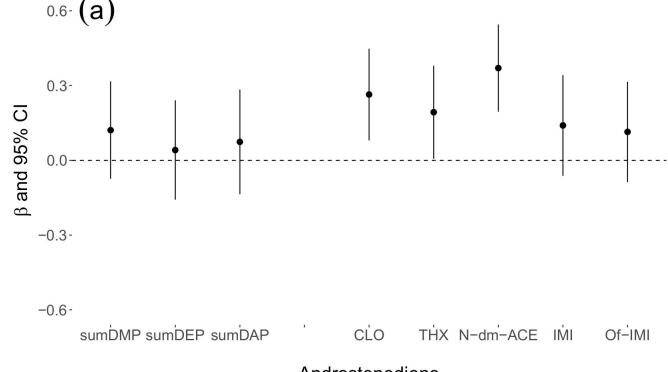

0.6. (c)

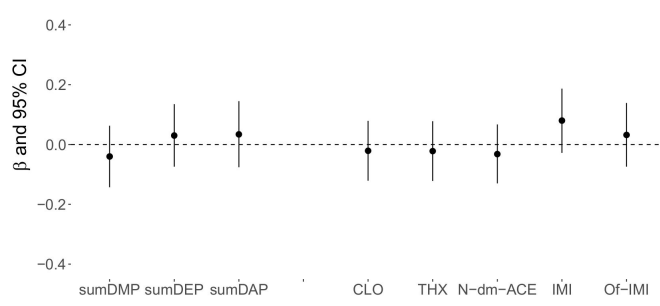

Cortisol

0.6. (e)

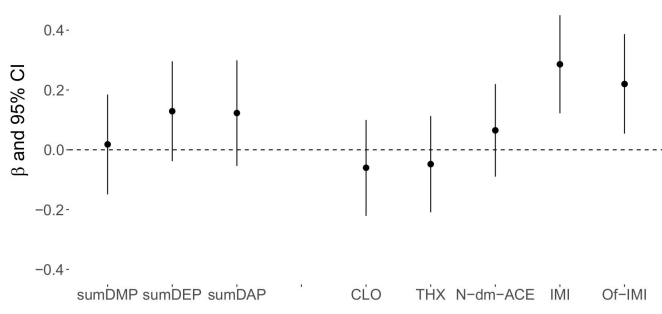

DHEA
$0.6 \cdot(\mathrm{b})$

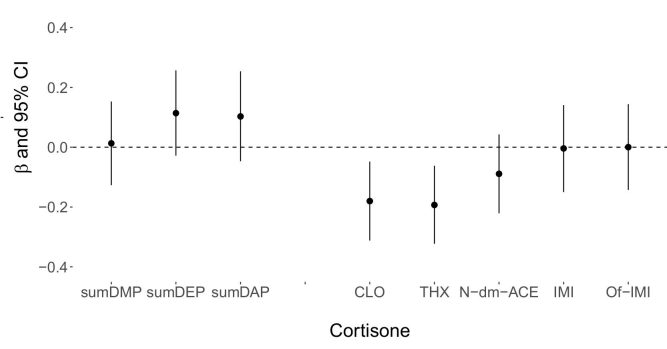

6. (d)

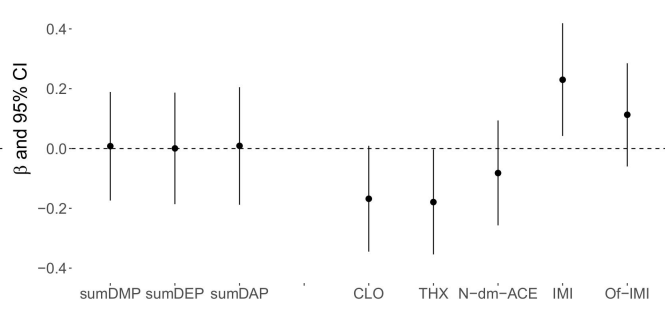

0.6. (f)

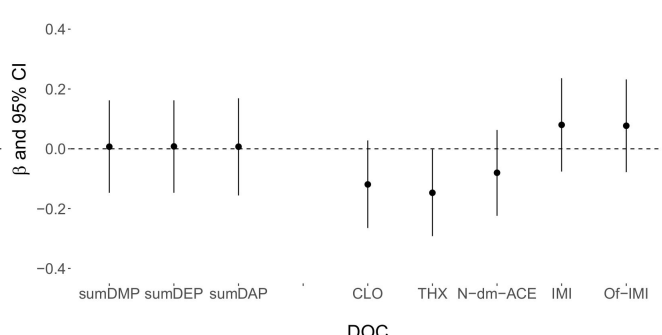

$0.6 \cdot(\mathrm{g})$

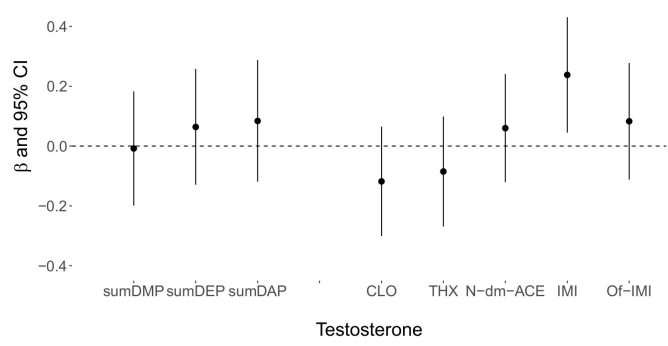

Figure 1. Linear regression models analyzing the association between each urinary concentration of DAP and NEO/m and serum levels of androstenedione (a), cortisol (b), cortisone (c), dehydrocorticosterone (d), dehydroepiandrosterone (e), deoxycorticosterone $(\mathbf{f})$ and testosterone $(\mathbf{g})$. The standardized partial regression coefficient $(\beta)$ and $95 \%$ confidence interval (CI) were presented as average change in dependent variable per one-unit change in the independent variable. The urinary concentrations of DAP were grouped as total of three dimethylalkylphosphate (sumDMP: DMP+DMTP+DMDTP), total of three diethylalkylphosphate (sumDEP: DEP+DETP+DEDTP), total of dialkylphosphates (sumDAP: sumDMP+sumDEP) and the urinary concentrations of NEO/m were shown as individual including CLO, THX, N-dm-ACE, IMI and Of-IMI. The same model was fitted for all the exposure measures: each urinary concentration of DAP and NEO/m was introduced into the linear regression model separately and adjusted for age, body mass index, smoking status, alcohol consumption, ethnicity, education level, monthly income, total number of years spent as a farmworker, status of farmworker, number of days per week and hours per day worked in the field, duration of last pesticide used prior to sample collection and hematological status. The independent variables were log10-transformed urinary concentrations of DAPs and NEO/m and the dependent variables were log-transformed serum steroid hormone. Abbreviations: DAP, dialkylphosphate; sumDMP, total of dimethylalkylphosphates; sumDMP, total of diethylalkylphosphates; sumDAP, total of dialkylphosphates; NEO/m, neonicotinoids and their metabolites; CLO, clothianidin; IMI, imidacloprid; THX, thiamethoxam; N-dm-ACE, N-desmethylacetamiprid; Of-IMI, imidacloprid-olefin; $\beta$, standardized partial regression coefficient; $\mathrm{CI}$, confidence interval. 


\section{Discussion}

Linear regression models revealed that $\mathrm{NEO} / \mathrm{m}$ concentrations were associated with serum steroid hormone concentrations. NEOs are classified as systemic insecticides [39] that are widely spread throughout the environment, which may explain why significant associations were found for concentrations of $\mathrm{NEO} / \mathrm{m}$ but not for concentrations of OP metabolites. Among NEO/m, the IMI level was positively associated with the DHC, DHEA and testosterone levels and there was a positive association between Of-IMI and DHEA levels. The THX level was negatively associated with the DHC and DOC levels. There were positive associations between the CLO, THX and N-dm-ACE levels and the androstenedione level as well as a negative association between the CLO and THX levels and the cortisone level. To the best of our knowledge, this is the first study to evaluate the effects of NEO/m concentrations on human serum steroid hormones. Our findings suggest that NEO exposure is associated with disruption of endocrine and reproductive functions.

\subsection{Serum Steroid Hormones}

A recent study reported that the normal reference range of the serum testosterone level is $2.1-9.7 \mathrm{ng} / \mathrm{mL}$ in fertile men $(n=120)$ [40]. In our study, the mean testosterone level was $6.5 \mathrm{ng} / \mathrm{mL}$ among male farmworkers. This is slightly higher than the mean level in the previous report $(4.8 \mathrm{ng} / \mathrm{mL})$. Most participants in the previous study were overweight or obese and a negative correlation between BMI and the testosterone level has been reported $[40,41]$. Furthermore, an epidemiological study reported that the mean testosterone levels in Thai male farmers and Venezuelan farmworkers were 7.4 and $6.7 \mathrm{ng} / \mathrm{mL}$, respectively, which is similar to the level in our study $[12,16]$. In comparison with our study, a lower testosterone level $(4.5 \mathrm{ng} / \mathrm{mL})$ was reported in Mexican male floriculture workers during intense pesticide spraying, but a similar level $(7.6 \mathrm{ng} / \mathrm{mL})$ was reported during less intense pesticide spraying [9]. This indicates that testosterone levels in our participants were within the normal range according to the World Health Organization guidelines and higher levels were found in males who had worked in agricultural fields for at least $1-20$ years $[9,16,42]$.

In addition to testosterone, the present study is the first to report the concentrations of several steroid hormones including androstenedione, cortisol, cortisone, DHC, DHEA and DOC among male farmworkers. Their concentrations were within the reference intervals compared with previously published values $[28,43]$.

\subsection{Associations between OP and NEO Exposure and Adrenal Androgen Hormones}

No epidemiological study has demonstrated an association between exposure to NEO insecticides and steroid hormones [44]. Most studies of reproductive toxicity induced by NEO insecticide used animals and focused on IMI and CLO. To the best of our knowledge, this is the first study to report associations between urinary NEO/m concentrations and adrenal androgen hormones including androstenedione, DHEA and testosterone in humans. We found positive associations of IMI and Of-IMI with DHEA ( $\beta=0.29 ; 95 \%$ CI: $0.12,0.45, \beta=0.22 ; 95 \%$ CI: $0.05,0.39$, respectively), and exposure to IMI and Of-IMI tended to be associated with an increasing androstenedione concentration. The testosterone level was positively associated with IMI and Of-IMI concentrations ( $\beta=0.24 ; 95 \%$ CI: $0.04,0.43$, $\beta=0.08 ; 95 \%$ CI: $-0.11,0.28$, respectively), which is inconsistent with animal studies [18]. A previous experimental study of male Wistar rats exposed to 45 and $90 \mathrm{mg} / \mathrm{kg} / \mathrm{body}$ weight IMI reported decreased enzymatic activity of $3 \beta$-hydroxysteroid dehydrogenase (3 $\beta$-HSD) and $17 \beta$-hydroxysteroid dehydrogenase (17 $\beta$-HSD), which catalyze conversion of DHEA to androstenedione and of androstenedione to testosterone, respectively, resulting in decreased testosterone concentrations $[28,45]$. The increased concentrations of DHEA, androstenedione and testosterone associated with exposure to IMI and Of-IMI suggest that adrenal androgen synthesis is promoted via induced expression of $3 \beta-\mathrm{HSD}$ type 2 (HSD3B2) and high CYP17A activity [46]. CYP17 enzymes including 17 $\alpha$-hydroxylase and 17,20 -lyase catalyze a step involved in formation of DHEA. 
There were positive associations between CLO, THX and N-dm-ACE levels and the androstenedione level ( $\beta=0.26$; 95\% CI: 0.08, 0.45, $\beta=0.19 ; 95 \% \mathrm{CI}: 0.01,0.38, \beta=0.37$; 95\% CI: 0.20, 0.54, respectively). However, exposure to CLO, THX and N-dm-ACE tended to be associated with decreasing DHEA and testosterone concentrations. HSD3B2 influences synthesis of DHEA (adrenal androgen), aldosterone (mineralocorticoid) and cortisol (glucocorticoid) by competing with CYP17. Additionally, low HSD3B2 expression and high CYP17 activity facilitates production of androgen, while high HSD3B2 expression and low CYP17 activity facilitates production of aldosterone [46]. CLO, THX and N-dm-ACE likely induce aldosterone production due to low CYP17 activity, which decreases the DHEA level, elevates HSD3B2 expression and consequently increases the androstenedione level. Interestingly, both CYP17 activity and HSD3B2 play an important role in regulation of adrenal androgen production and different NEO insecticides influenced CYP17 activity disparately in our study.

$17 \beta-H S D$ is involved in formation of testosterone and has five isoforms [47]. A previous study of human tissues showed that 17 $\beta$-HSD type 2 (HSD17B2) degrades estradiol into estrone (estrogens) and testosterone into androstenedione. In addition, 17 $\beta$-HSD type 3 (HSD17B3) and type 5 (HSD17B5) catalyze formation of testosterone in testes and peripheral tissues, respectively [47]. We speculate that exposure to different NEOs interferes with $17 \beta-H S D$ gene expression in a different manner, resulting in different effects on the testosterone level. Moreover, the testosterone level could be altered due to changes in the LH level upon exposure to insecticides [9]. Our findings suggest that human exposure to NEOs induces the hypothalamic-pituitary-adrenal axis through adrenal androgen biosynthesis pathways. Further studies are needed to confirm our findings and to elucidate the underlying mechanisms.

Another possible explanation for association between exposure to NEO and adrenal androgen hormones is NEO agonistic or antagonistic interaction with hormone receptors including androgen receptor (AR) and estrogen receptor (ER) [48]. Both AR and ER are potentially involved in mediating the action of sex steroid hormones [49,50]. An animal study on male mice showed IMI decreases testosterone, can interact with AR and decrease AR expression in the testes [51]. A study of endocrine activities of THX and ACE found in waste water effluent using yeast-based bioassays showed weak antagonist androgen activity and antagonist estrogen activity for THI [52]. The molecular study of Zhang et al. (2020) revealed that IMI and THI can interfere with estrogen induced signaling [48]. Therefore, NEO mimics or disturbs the action of natural hormones, which may alter the synthesis, metabolism, transport of the hormones. We speculate that NEO may have agonist or antagonist activities at the AR and ER which caused alteration on the steroid and reproductive hormones syntheses, metabolisms and transport of the hormones. Due to limited information, more research is needed to elucidate the endocrine activity of NEO insecticides.

Several previous epidemiological studies found associations between testosterone and exposure to OP insecticides by measuring DAP metabolites in urine $[9,15,16,53]$. In our study, there was no significant association between testosterone level and urinary DAP concentrations. These findings are consistent with a previous study of Mexican agricultural workers, which suggested that OP metabolites overall have lesser effects than specific metabolites [53]. Furthermore, significant positive associations between concentrations of OP metabolites and testosterone were observed among Thai farmers and Mexican floriculture workers $[14,16]$. However, a longitudinal study showed a significant negative association between concentrations of OP metabolites and the testosterone level [9]. A decreased testosterone level associated with the chlorpyrifos concentration was observed among fertile and infertile men [10].

\subsection{Associations between OP and NEO Exposure and Glucocorticoids and Mineralocorticoids}

In this study, CLO and THX concentrations were inversely associated with the cortisone concentration, inconsistent with an animal study [54]. In that study, treatment of rats 
with IMI resulted in stress and increased the cortisone level, suggesting that IMI disrupts glucose homeostasis [54]. These findings indicate that exposure to NEO insecticides alters glucocorticoids including cortisone and mineralocorticoids including DHC and DOC. Furthermore, we did not find any association between DAPs and steroid hormones. Further research is warranted to reveal the endocrine disrupting activities of OPs and NEOs among the general population.

\subsection{Limitations}

This study found associations between NEO exposure and steroid hormones including androstenedione, DHEA, DHC, DOC, cortisone and testosterone, but has some limitations. First, this cross-sectional study limited causal inference. Furthermore, prospective studies are needed to confirm the results. DAPs and NEOs have short half-lives in humans [55,56]. Data regarding historic pesticide use must be collected. Previous studies found that urinary concentrations of DAP metabolites and some NEO/m do not adequately reflect exposure for over 1 month $[57,58]$. Spot urine and blood samples were collected after breakfast and before lunch to keep the sampling period short. OP and NEO insecticides have a toxic effect on the hypothalamic pituitary gonadal (HPG) axis, which regulates the synthesis and secretion of sex hormones [9]. The HPG axis-involved hormones including gonadotropin releasing hormones, $\mathrm{LH}, \mathrm{FSH}$, inhibin $\mathrm{B}$, progesterone and estradiol should be investigated to clarify the mechanism of OP and NEO impacts on these hormones. Another limitation is that the adjusted $\mathrm{R}^{2}$ was relatively small in multivariate regression models, particularly for androstenedione and testosterone. A further study should consider potential factors affecting the androgen axis.

\section{Conclusions}

The key result of this study is that exposure to NEO insecticides is associated with steroid hormones among male farmworkers. IMI and Of-IMI levels were positively associated with androstenedione, cortisol, cortisone, DHEA, DHC, DOC and testosterone levels; however, the levels of CLO, THX and N-dm-ACE showed a negative trend with levels of hormones, except for androstenedione. We speculate that exposure to different NEO insecticides elicits opposite effects on expression of steroid enzymes and hormone receptor binding. Exposure to systemic insecticides disrupts steroidogenesis and may adversely affect the reproductive system among people of reproductive age. There are no previous human studies of this topic, and the results of animal studies are inconsistent with our human study. Therefore, human studies of exposure to OP and NEO insecticides and its impact on steroid hormones are needed in other populations.

Supplementary Materials: The following are available online at https:/ / www.mdpi.com/article/10 .3390 /ijerph18115599/s1, Table S1: Spearman's correlation coefficients between general characteristics and urinary DAP and NEO/m concentrations.

Author Contributions: Conceptualization, N.S., T.P. (Tippawan Prapamontol) and S.F.N.; methodology, N.S., T.P. (Tippawan Prapamontol), T.I., Y.N., Y.H., A.M., T.P. (Tawiwan Pantasri), S.C., W.N. and S.F.N., data curation, N.S., T.P. (Tippawan Prapamontol), T.I., Y.N. and S.F.N.; writing-original draft preparation, N.S.; writing-review and editing, N.S., T.P. (Tippawan Prapamontol), T.I., Y.N., A.M., T.P. (Tawiwan Pantasri), S.C., W.N. and S.F.N.; supervision, T.P. (Tippawan Prapamontol), T.I. and S.F.N. All authors have read and agreed to the published version of the manuscript.

Funding: This project was supported by the 50th Anniversary Chiang Mai University-Ph.D. scholarship, grant number: Ph.D.003/2557 and Health and Environmental Risk Division, National Institute for Environmental Studies (NIES), Tsukuba, Japan.

Institutional Review Board Statement: The study was conducted according to the guidelines of the Declaration of Helsinki and approved by the ethics committee of the Research Institute for Health Sciences (RIHES), Chiang Mai University (Project no. 5/62, approved on 7 June 2019) as well as by the Institutional Review Board of the National Institute for Environmental Studies (NIES), Japan (Project no. NIES2019-005, approved on 24 October 2019). 
Informed Consent Statement: Informed consent was obtained from all subjects involved in the study.

Acknowledgments: The authors would like to thank the Research Institute for Health Sciences (RIHES), Chiang Mai University, Chiang Mai, Thailand and the National Institute for Environmental Studies (NIES), Tsukuba, Japan, which supported the laboratory facilities, and the Study of Asian Women and Offspring's Development and Environmental Exposure (SAWASDEE) funded by the National Institute of Health (NIH) (grant number RO1ES026082) in northern Thailand for providing the instruments at SAWASDEE laboratory in Fang district, Chiang Mai province. The authors would also like to thank the farmworkers in Fang district of Chiang Mai province who participated in this study, and the project staff, health-promoting hospital staff and community leaders who helped to collect the data and biological samples and to promote the project.

Conflicts of Interest: The authors declare no conflict of interest.

\section{References}

1. Quandt, S.A.; Hernández-Valero, M.A.; Grzywacz, J.G.; Hovey, J.D.; Gonzales, M.; Arcury, T.A. Workplace, Household, and Personal Predictors of Pesticide Exposure for Farmworkers. Environ. Health Perspect. 2006, 114, 943-952. [CrossRef] [PubMed]

2. Fiedler, N.; Rohitrattana, J.; Siriwong, W.; Suttiwan, P.; Strickland, P.O.; Ryan, P.B.; Rohlman, D.S.; Panuwet, P.; Barr, D.B.; Robson, M.G. Neurobehavioral effects of exposure to organophosphates and pyrethroid pesticides among Thai children. Neurotoxicology 2015, 48, 90-99. [CrossRef] [PubMed]

3. Casadó, L.; Arrebola, J.P.; Fontalba-Navas, A.; Muñoz, A. Adverse effects of hexaclorobenzene exposure in children and adolescents. Environ. Res. 2019, 176, 108421. [CrossRef] [PubMed]

4. Mostafalou, S.; Abdollahi, M. Pesticides: An update of human exposure and toxicity. Arch. Toxicol. 2017, 91, 549-599. [CrossRef]

5. Sifakis, S.; Androutsopoulos, V.P.; Tsatsakis, A.M.; Spandidos, D.A. Human exposure to endocrine disrupting chemicals: Effects on the male and female reproductive systems. Environ. Toxicol. Pharmacol. 2017, 51, 56-70. [CrossRef]

6. Orta, O.R.; Wesselink, A.K.; Bethea, T.N.; Henn, B.C.; Sjödin, A.; Wegienka, G.; Baird, D.D.; Wise, L.A. Correlates of organochlorine pesticide plasma concentrations among reproductive-aged black women. Environ. Res. 2020, 184, 109352. [CrossRef]

7. Hauser, R.; Meeker, J.; Park, S.; Silva, M.J.; Calafat, A.M. Temporal Variability of Urinary Phthalate Metabolite Levels in Men of Reproductive Age. Environ. Health Perspect. 2004, 112, 1734-1740. [CrossRef]

8. Omoike, O.E.; Lewis, R.C.; Meeker, J.D. Association between urinary biomarkers of exposure to organophosphate insecticides and serum reproductive hormones in men from NHANES 1999-2002. Reprod. Toxicol. 2015, 53, 99-104. [CrossRef]

9. Aguilar-Garduño, C.; Lacasaña, M.; Blanco-Muñoz, J.; Rodríguez-Barranco, M.; Hernández, A.; Bassol, S.; González-Alzaga, B.; Cebrián, M. Changes in male hormone profile after occupational organophosphate exposure. A longitudinal study. Toxicology 2013, 307, 55-65. [CrossRef]

10. Meeker, J.; Ryan, L.; Barr, D.B.; Hauser, R. Exposure to Nonpersistent Insecticides and Male Reproductive Hormones. Epidemiology 2006, 17, 61-68. [CrossRef]

11. Lacasaña, M.; López-Flores, I.; Rodríguez-Barranco, M.; Aguilar-Garduño, C.; Blanco-Muñoz, J.; Pérez-Méndez, O.; Gamboa, R.; Bassol, S.; Cebrian, M.E. Association between organophosphate pesticides exposure and thyroid hormones in floriculture workers. Toxicol. Appl. Pharmacol. 2010, 243, 19-26. [CrossRef]

12. Miranda-Contreras, L.; Gómez-Pérez, R.; Rojas, G.; Cruz, I.; Berrueta, L.; Salmen, S.; Colmenares, M.; Barreto, S.; Balza, A.; Zavala, L.; et al. Occupational Exposure to Organophosphate and Carbamate Pesticides Affects Sperm Chromatin Integrity and Reproductive Hormone Levels among Venezuelan Farm Workers. J. Occup. Health 2013, 55, 195-203. [CrossRef] [PubMed]

13. Asawasinsopon, R.; Prapamontol, T.; Prakobvitayakit, O.; Vaneesorn, Y.; Mangklabruks, A.; Hock, B. Plasma levels of DDT and their association with reproductive hormones in adult men from northern Thailand. Sci. Total. Environ. 2006, 355, 98-105. [CrossRef]

14. Blanco-Muñoz, J.; Morales, M.M.; Lacasaña, M.; Aguilar-Garduño, C.; Bassol, S.; Cebrián, M.E. Exposure to organophosphate pesticides and male hormone profile in floriculturist of the state of Morelos, Mexico. Hum. Reprod. 2010, 25, 1787-1795. [CrossRef] [PubMed]

15. Melgarejo, M.; Mendiola, J.; Koch, H.M.; Moñino-García, M.; Noguera-Velasco, J.A.; Torres-Cantero, A.M. Associations between urinary organophosphate pesticide metabolite levels and reproductive parameters in men from an infertility clinic. Environ. Res. 2015, 137, 292-298. [CrossRef]

16. Panuwet, P.; Ladva, C.; Barr, D.B.; Prapamontol, T.; Meeker, J.; D’Souza, P.E.; Maldonado, H.; Ryan, P.B.; Robson, M.G. Investigation of associations between exposures to pesticides and testosterone levels in Thai farmers. Arch. Environ. Occup. Health 2018, 73, 205-218. [CrossRef] [PubMed]

17. Kapoor, U.; Srivastava, M.; Srivastava, L. Toxicological impact of technical imidacloprid on ovarian morphology, hormones and antioxidant enzymes in female rats. Food Chem. Toxicol. 2011, 49, 3086-3089. [CrossRef]

18. Bal, R.; Naziroğlu, M.; Türk, G.; Yilmaz, Ö.; Kuloğlu, T.; Etem, E.; Baydas, G. Insecticide imidacloprid induces morphological and DNA damage through oxidative toxicity on the reproductive organs of developing male rats. Cell Biochem. Funct. 2012, 30, 492-499. [CrossRef] 
19. Bal, R.; Türk, G.; Yılmaz, Ö.; Etem, E.; Kuloğlu, T.; Baydaş, G.; Naziroğlu, M. Effects of clothianidin exposure on sperm quality, testicular apoptosis and fatty acid composition in developing male rats. Cell Biol. Toxicol. 2012, 28, 187-200. [CrossRef]

20. Bal, R.; Türk, G.; Tuzcu, M.; Yılmaz, Ö.; Kuloğlu, T.; Baydaş, G.; Naziroğlu, M.; Yener, Z.; Etem, E.; Tuzcu, Z. Effects of the neonicotinoid insecticide, clothianidin, on the reproductive organ system in adult male rats. Drug Chem. Toxicol. 2013, 36, 421-429. [CrossRef]

21. Gu, Y.-H.; Li, Y.; Huang, X.-F.; Zheng, J.-F.; Yang, J.; Diao, H.; Yuan, Y.; Xu, Y.; Liu, M.; Shi, H.-J.; et al. Reproductive Effects of Two Neonicotinoid Insecticides on Mouse Sperm Function and Early Embryonic Development In Vitro. PLoS ONE 2013, 8, e70112. [CrossRef] [PubMed]

22. Sano, K.; Isobe, T.; Yang, J.; Win-Shwe, T.T.; Yoshikane, M.; Nakayama, S.F.; Kawashima, T.; Suzuki, G.; Hashimoto, S.; Nohara, K.; et al. In utero and Lactational Exposure to Acetamiprid Induces Abnormalities in Socio-Sexual and Anxiety-Related Behaviors of Male Mice. Front. Neurosci. 2016, 10, 228. [CrossRef] [PubMed]

23. Cimino, A.M.; Boyles, A.; Thayer, K.A.; Perry, M.J. Effects of Neonicotinoid Pesticide Exposure on Human Health: A Systematic Review. Environ. Health Perspect. 2017, 125, 155-162. [CrossRef] [PubMed]

24. Yang, W.; Carmichael, S.L.; Roberts, E.M.; Kegley, S.E.; Padula, A.M.; English, P.B.; Shaw, G.M. Residential Agricultural Pesticide Exposures and Risk of Neural Tube Defects and Orofacial Clefts Among Offspring in the San Joaquin Valley of California. Am. J. Epidemiol. 2014, 179, 740-748. [CrossRef] [PubMed]

25. Carmichael, S.L.; Yang, W.; Roberts, E.; Kegley, S.E.; Padula, A.M.; English, P.B.; Lammer, E.J.; Shaw, G.M. Residential agricultural pesticide exposures and risk of selected congenital heart defects among offspring in the San Joaquin Valley of California. Environ. Res. 2014, 135, 133-138. [CrossRef] [PubMed]

26. Ichikawa, G.; Kuribayashi, R.; Ikenaka, Y.; Ichise, T.; Nakayama, S.M.M.; Ishizuka, M.; Taira, K.; Fujioka, K.; Sairenchi, T.; Kobashi, G.; et al. LC-ESI/MS/MS analysis of neonicotinoids in urine of very low birth weight infants at birth. PLoS ONE 2019, 14, e0219208. [CrossRef] [PubMed]

27. Koureas, M.; Tsezou, A.; Tsakalof, A.; Orfanidou, T.; Hadjichristodoulou, C. Increased levels of oxidative DNA damage in pesticide sprayers in Thessaly Region (Greece). Implications of pesticide exposure. Sci. Total. Environ. 2014, 496, 358-364. [CrossRef]

28. Kushnir, M.M.; Blamires, T.; Rockwood, A.L.; Roberts, W.L.; Yue, B.; Erdogan, E.; Bunker, A.M.; Meikle, A.W. Liquid Chromatography-Tandem Mass Spectrometry Assay for Androstenedione, Dehydroepiandrosterone, and Testosterone with Pediatric and Adult Reference Intervals. Clin. Chem. 2010, 56, 1138-1147. [CrossRef]

29. Araki, A.; Miyashita, C.; Mitsui, T.; Goudarzi, H.; Mizutani, F.; Chisaki, Y.; Itoh, S.; Sasaki, S.; Cho, K.; Moriya, K.; et al. Prenatal organochlorine pesticide exposure and the disruption of steroids and reproductive hormones in cord blood: The Hokkaido study. Environ. Int. 2018, 110, 1-13. [CrossRef]

30. Kulle, A.E.; Welzel, M.; Holterhus, P.-M.; Riepe, F.G. Implementation of a Liquid Chromatography Tandem Mass Spectrometry Assay for Eight Adrenal C-21 Steroids and Pediatric Reference Data. Horm. Res. Paediatr. 2013, 79, 22-31. [CrossRef]

31. Suwannarin, N.; Prapamontol, T.; Isobe, T.; Nishihama, Y.; Nakayama, S.F. Characteristics of Exposure of Reproductive-Age Farmworkers in Chiang Mai Province, Thailand, to Organophosphate and Neonicotinoid Insecticides: A Pilot Study. Int. J. Environ. Res. Public Health 2020, 17, 7871. [CrossRef] [PubMed]

32. Kongtip, P.; Nankongnab, N.; Pundee, R.; Kallayanatham, N.; Pengpumkiat, S.; Chungcharoen, J.; Phommalachai, C.; Konthonbut, P.; Choochouy, N.; Sowanthip, P.; et al. Acute Changes in Thyroid Hormone Levels among Thai Pesticide Sprayers. Toxics 2021, 9, 16. [CrossRef] [PubMed]

33. Meeker, J.D.; Ravi, S.R.; Barr, D.B.; Hauser, R. Circulating estradiol in men is inversely related to urinary metabolites of nonpersistent insecticides. Reprod. Toxicol. 2008, 25, 184-191. [CrossRef] [PubMed]

34. Prapamontol, T.; Sutan, K.; Laoyang, S.; Hongsibsong, S.; Lee, G.; Yano, Y.; Hunter, R.E.; Ryan, P.B.; Barr, D.B.; Panuwet, P. Cross validation of gas chromatography-flame photometric detection and gas chromatography-mass spectrometry methods for measuring dialkylphosphate metabolites of organophosphate pesticides in human urine. Int. J. Hyg. Environ. Health 2014, 217, 554-566. [CrossRef]

35. Zhou, H.; Wang, Y.; Gatcombe, M.; Farris, J.; Botelho, J.C.; Caudill, S.P.; Vesper, H.W. Simultaneous measurement of total estradiol and testosterone in human serum by isotope dilution liquid chromatography tandem mass spectrometry. Anal. Bioanal. Chem. 2017, 409, 5943-5954. [CrossRef]

36. Gaudl, A.; Kratzsch, J.; Ceglarek, U. Advancement in steroid hormone analysis by LC-MS/MS in clinical routine diagnostics-A three year recap from serum cortisol to dried blood $17 \alpha$-hydroxyprogesterone. J. Steroid Biochem. Mol. Biol. 2019, 192, 105389. [CrossRef]

37. Just, A.C.; Adibi, J.J.; Rundle, A.G.; Calafat, A.M.; Camann, D.E.; Hauser, R.; Silva, M.J.; Whyatt, R.M. Urinary and air phthalate concentrations and self-reported use of personal care products among minority pregnant women in New York city. J. Expo. Sci. Environ. Epidemiol. 2010, 20, 625-633. [CrossRef]

38. Anuurad, E.; Shiwaku, K.; Nogi, A.; Kitajima, K.; Enkhmaa, B.; Shimono, K.; Yamane, Y. The New BMI Criteria for Asians by the Regional Office for the Western Pacific Region of WHO are Suitable for Screening of Overweight to Prevent Metabolic Syndrome in Elder Japanese Workers. J. Occup. Health 2003, 45, 335-343. [CrossRef]

39. Jeschke, P.; Nauen, R.; Schindler, M.; Elbert, A. Overview of the Status and Global Strategy for Neonicotinoids. J. Agric. Food Chem. 2011, 59, 2897-2908. [CrossRef] 
40. Pruktanakul, T.; Taemkaew, K.; Liabsuetrakul, T.; Leelawattana, R.; Kietsiriroje, N. Normal Reference Ranges of Serum Testosterone and Gonadotropins in Thai Fertile Men: A Cross-sectional Study in a Single Tertiary Center. J. Health Sci. Med. Res. 2020, 39, 123-133. [CrossRef]

41. Shamim, M.O.; Khan, F.M.A.; Arshad, R. Association between serum total testosterone and Body Mass Index in middle aged healthy men. Pak. J. Med. Sci. 2015, 31, 355-359. [CrossRef] [PubMed]

42. Panuwet, P.; Prapamontol, T.; Chantara, S.; Thavornyuthikarn, P.; Montesano, M.; Whitehead, R.; Barr, D. Concentrations of urinary pesticide metabolites in small-scale farmers in Chiang Mai Province, Thailand. Sci. Total. Environ. 2008, 407, 655-668. [CrossRef] [PubMed]

43. Dahl, S.R.; Nermoen, I.; Brønstad, I.; Husebye, E.S.; Løvås, K.; Thorsby, P.M. Assay of steroids by liquid chromatography-tandem mass spectrometry in monitoring 21-hydroxylase deficiency. Endocr. Connect. 2018, 7, 1542-1550. [CrossRef] [PubMed]

44. Thompson, D.A.; Lehmler, H.-J.; Kolpin, D.W.; Hladik, M.L.; Vargo, J.D.; Schilling, K.E.; LeFevre, G.H.; Peeples, T.L.; Poch, M.C.; LaDuca, L.E.; et al. A critical review on the potential impacts of neonicotinoid insecticide use: Current knowledge of environmental fate, toxicity, and implications for human health. Environ. Sci. Process. Impacts 2020, 22, 1315-1346. [CrossRef] [PubMed]

45. Lonare, M.; Kumar, M.; Raut, S.; More, A.; Doltade, S.; Badgujar, P.; Telang, A. Evaluation of ameliorative effect of curcumin on imidacloprid-induced male reproductive toxicity in wistar rats. Environ. Toxicol. 2016, 31, 1250-1263. [CrossRef]

46. Rainey, W.E.; Nakamura, Y. Regulation of the adrenal androgen biosynthesis. J. Steroid Biochem. Mol. Biol. 2008, 108, 281-286. [CrossRef]

47. Labrie, F.; Luu-The, V.; Lin, S.-X.; Labrie, C.; Simard, J.; Breton, R.; Bélanger, A. The key role of 17ß-hydroxysteroid dehydrogenases in sex steroid biology. Steroids 1997, 62, 148-158. [CrossRef]

48. Zhang, C.; Schilirò, T.; Gea, M.; Bianchi, S.; Spinello, A.; Magistrato, A.; Gilardi, G.; Di Nardo, G. Molecular Basis for Endocrine Disruption by Pesticides Targeting Aromatase and Estrogen Receptor. Int. J. Environ. Res. Public Health 2020, 17, 5664. [CrossRef] [PubMed]

49. Purves-Tyson, T.D.; Arshi, M.S.; Handelsman, D.J.; Cheng, Y.; Keast, J.R. Androgen and estrogen receptor mediated mechanisms of testosterone action in male rat pelvic autonomic ganglia. Bone 2012, 23, 1-7. [CrossRef] [PubMed]

50. Hamid, N.; Junaid, M.; Pei, D.-S. Combined toxicity of endocrine-disrupting chemicals: A review. Ecotoxicol. Environ. Saf. 2021, 215, 112136. [CrossRef]

51. Yuan, X.; Shen, J.; Zhang, X.; Tu, W.; Fu, Z.; Jin, Y. Imidacloprid disrupts the endocrine system by interacting with androgen receptor in male mice. Sci. Total. Environ. 2020, 708, 135163. [CrossRef] [PubMed]

52. Westlund, P.; Yargeau, V. Investigation of the presence and endocrine activities of pesticides found in wastewater effluent using yeast-based bioassays. Sci. Total. Environ. 2017, 607-608, 744-751. [CrossRef] [PubMed]

53. Recio, R.; Ocampo-Gómez, G.; Morán-Martínez, J.; Borja-Aburto, V.; López-Cervantes, M.; Uribe, M.; Torres-Sánchez, L.; Cebrián, M.E. Pesticide Exposure Alters Follicle-Stimulating Hormone Levels in Mexican Agricultural Workers. Environ. Health Perspect. 2005, 113, 1160-1163. [CrossRef] [PubMed]

54. Khalil, S.R.; Awad, A.; Mohammed, H.H.; Nassan, M.A. Imidacloprid insecticide exposure induces stress and disrupts glucose homeostasis in male rats. Environ. Toxicol. Pharmacol. 2017, 55, 165-174. [CrossRef] [PubMed]

55. Barr, D.B.; Angerer, J. Potential Uses of Biomonitoring Data: A Case Study Using the Organophosphorus Pesticides Chlorpyrifos and Malathion. Environ. Health Perspect. 2006, 114, 1763-1769. [CrossRef] [PubMed]

56. Harada, K.H.; Tanaka, K.; Sakamoto, H.; Imanaka, M.; Niisoe, T.; Hitomi, T.; Kobayashi, H.; Okuda, H.; Inoue, S.; Kusakawa, K.; et al. Biological Monitoring of Human Exposure to Neonicotinoids Using Urine Samples, and Neonicotinoid Excretion Kinetics. PLoS ONE 2016, 11, e0146335. [CrossRef]

57. Li, A.J.; Martinez-Moral, M.-P.; Kannan, K. Variability in urinary neonicotinoid concentrations in single-spot and first-morning void and its association with oxidative stress markers. Environ. Int. 2020, 135, 105415. [CrossRef]

58. Spaan, S.; Pronk, A.; Koch, H.M.; Jusko, T.A.; Jaddoe, V.W.; Shaw, P.A.; Tiemeier, H.M.; Hofman, A.; Pierik, F.H.; Longnecker, M.P. Reliability of concentrations of organophosphate pesticide metabolites in serial urine specimens from pregnancy in the Generation R Study. J. Expo. Sci. Environ. Epidemiol. 2015, 25, 286-294. [CrossRef] 